\title{
Luminescence of $\mathrm{K}_{5} \mathrm{Li}_{2} \mathrm{CeF}_{10}$ and $\mathrm{K}_{5} \mathrm{Li}_{2} \mathrm{LaF}_{10}: \mathrm{Ce}^{3+}$
}

\author{
Piotr Solarz ${ }^{\mathrm{a}, *}$, Winiciusz Drozdowski ${ }^{\mathrm{b}}$, Witold Ryba-Romanowski ${ }^{\mathrm{a}}$ \\ ${ }^{a}$ Institute of Low Temperature and Structure Research, Polish Academy of Sciences, ul. Okólna 2, PL-50422 Wroctaw, Poland \\ ${ }^{\mathrm{b}}$ Institute of Physics, Nicolaus Copernicus University, ul. Grudziadzka 5/7, PL-87100 Toruń, Poland
}

Available online 10 March 2006

\begin{abstract}
The positions of $4 \mathrm{f}-5 \mathrm{~d}$ levels of cerium in $\mathrm{K}_{5} \mathrm{Li}_{2} \mathrm{LaF}_{10}$ crystals were determined to be situated at: $33145 \mathrm{~cm}^{-1}$ (zero phonon line), $43700,45900,47250$ and $54500 \mathrm{~cm}^{-1}$. Thermoluminescence glow curves, depend on concentration of Ce $\mathrm{e}^{3+}$ and reveals occurrence of several traps with depths ranging from $0.3-0.84 \mathrm{eV}$; the low value of ratio $\mathrm{TL} /(\mathrm{TL}+\mathrm{ssRL})$ for $\mathrm{K}_{5} \mathrm{Li}_{2} \mathrm{CeF}_{10}(0.07)$ suggests that the trapping process is almost negligible in contrast to the $\mathrm{K}_{5} \mathrm{Li}_{2} \mathrm{La}_{0.99} \mathrm{Ce}_{0.03} \mathrm{~F}_{10}(0.44)$ one, where nearly half of the excitation energy is stored in traps.
\end{abstract}

(C) 2006 Elsevier B.V. All rights reserved.

Keywords: Thermoluminescence; VUV; Cerium; Fluoride crystal

\section{Introduction}

The scientific research on phosphors has a long history, it started more than 100 years ago. Recently, the investigation goes on three paths mainly: plasma displays and mercury-free efficient lamps [1-3]; scintillators for VUV-X-ray [4-6]; fast scintillators for gamma radiation using core-valence luminescence [7-10]. Besides these reasons the fundamental research is still attractive to give the possibility to predict theoretically the properties of new material, to reduce costs of investigations. Compounds doped with cerium, which can be used as scintillators, give information about behaviour of other lanthanide dopands, especially on $\mathrm{f}-\mathrm{d}$ transition [11]. In this communication we present some results of our studies on spectroscopic and scintillation properties of $\mathrm{K}_{5} \mathrm{Li}_{2} \mathrm{CeF}_{10}$ and $\mathrm{K}_{5} \mathrm{Li}_{2} \mathrm{LaF}_{10}$ : $\mathrm{Ce}$ single crystals. Crystals under study are uncommon in that the rare-earth ions do not share ligands between themselves, and are well spaced. Owing to this feature, the selfquenching of luminescence is strongly reduced, consequently the concentration of lanthanide ions can be maintained at a high-level without loss of emission efficiency.

\footnotetext{
*Corresponding author. Fax: +48713441029.

E-mail address: solarz@int.pan.wroc.pl (P. Solarz).
}

\section{Materials and experimental}

Single crystals of $\mathrm{K}_{5} \mathrm{Li}_{2} \mathrm{CeF}_{10}$ and $\mathrm{K}_{5} \mathrm{Li}_{2} \mathrm{LaF}_{10}$ :Ce were grown using the Bridgman process in graphite crucibles (IG-110). Excitation spectra, luminescence decay times, and the VUV-excited luminescence spectra were recorded using synchrotron radiation at the SUPERLUMI and HIGITI stations of the Synchrotronstrahlungslabor at DESY in Hamburg. Thermoluminescence spectra (TL) were recorded using a typical set-up consisting of an X-ray tube operated at $44 \mathrm{kV}$ and $6 \mathrm{~mA}$, a $0.5 \mathrm{~m}$ monochromator (Acton Research Corporation SpectraPro-500), a photomultiplier (Hamamatsu R928), and a closed-cycle helium cooler (APD Cryogenics, Inc.) with a programmable temperature controller (Lake Shore 330). Prior to the TL runs, the samples were exposed for $10 \mathrm{~min}$ to $\mathrm{X}$-rays at a temperature of $10 \mathrm{~K}$. The glow curves were recorded between 10 and $300 \mathrm{~K}$ at a heating rate of about $0.15 \mathrm{~K} / \mathrm{s}$.

\section{Results and discussion}

Although the luminescence, absorption and excitation spectra of $\mathrm{Ce}^{3+}$ in $\mathrm{K}_{5} \mathrm{Li}_{2} \mathrm{LaF}_{10}$ were presented elsewhere [12] for 3 and 100 at $\%$ of cerium, the detailed information about the $5 \mathrm{~d}$ levels was not clear. Fig. 1 presents emission and excitation spectra of $\mathrm{K}_{5} \mathrm{Li}_{2} \mathrm{LaF}_{10}$ doped with 0.1 at $\%$ of $\mathrm{Ce}^{3+}$ at $8 \mathrm{~K}$. The strong emission, with temperature 


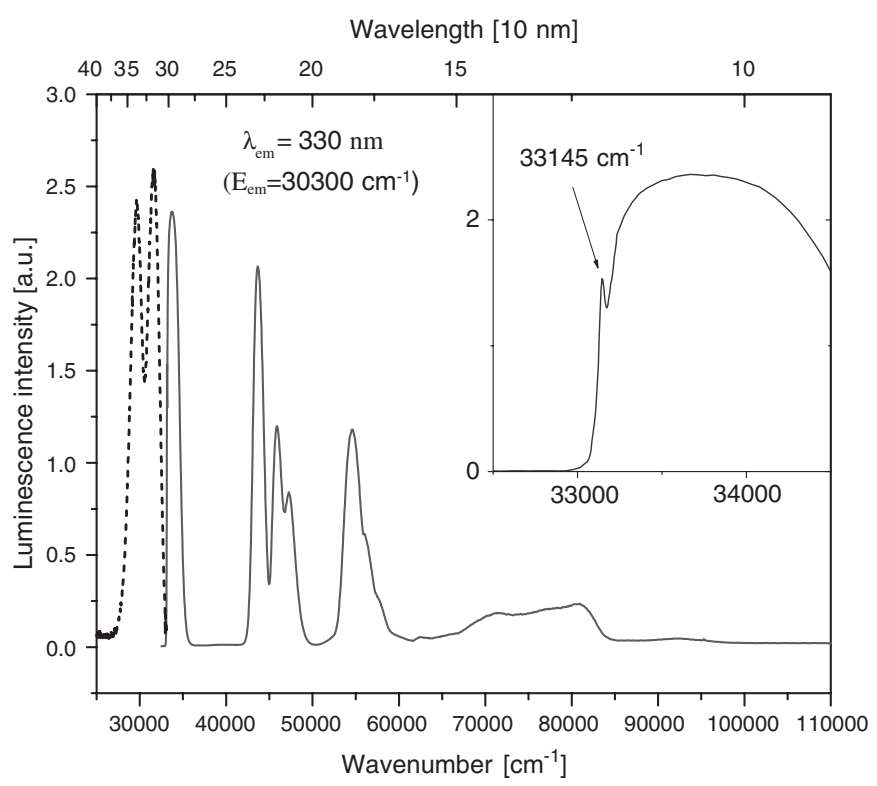

Fig. 1. Emission (dashed line) and excitation solid line of $\mathrm{K}_{5} \mathrm{Li}_{2} \mathrm{La}_{0.999}$ $\mathrm{Ce}_{0.001} \mathrm{~F}_{10}$ recorded at $8 \mathrm{~K}$. Inset presents the position of the zero-phonon line of $\mathrm{f}-\mathrm{d}$ transition.

independent life time $\sim 32 \mathrm{~ns}$, band is composed from transitions from the lowest $5 \mathrm{~d}$ state to the excited ${ }^{2} \mathrm{~F}_{7 / 2}$ $\left(29610 \mathrm{~cm}^{-1}\right)$ and ground ${ }^{2} \mathrm{~F}_{5 / 2}\left(31550 \mathrm{~cm}^{-1}\right)$ states, in good agreement with the data presented in Ref. [12]. An energy difference of about $1940 \mathrm{~cm}^{-1}$, which is a typical value for the spin-orbit split of the states ${ }^{2} \mathrm{~F}_{7 / 2}$ and ${ }^{2} \mathrm{~F}_{5 / 2}$ of $\mathrm{Ce}^{3+}$ ion, confirms the $\mathrm{Ce}^{3+} \mathrm{d}-\mathrm{f}$ nature of this emission, excited at $54500 \mathrm{~cm}^{-1}$. X-ray excitation brings about the same emission band in $\mathrm{K}_{5} \mathrm{Li}_{2} \mathrm{La}_{0.97} \mathrm{Ce}_{0.03} \mathrm{~F}_{10}$.

Upon excitation at the band $70000-80000 \mathrm{~cm}^{-1}$ selftrapped excitons (STE) luminescence can be observed, with maximum at $\sim 23000 \mathrm{~cm}^{-1}$. This emission disappears at higher temperatures. For higher concentration of cerium the ratio of this STE emission to d-f one decreases. The decay, of this broad-band emission in the visible, is slower by orders of magnitude with respect to the $\mathrm{d}-\mathrm{f}$ one. The intensity of the excitation spectrum slowly goes down, when the excitation energy is higher, and at near $81080 \mathrm{~cm}^{-1}(123 \mathrm{~nm}, 10 \mathrm{eV})$ rapidly goes to zero. This point is consistent with the absorption edge of the host.

The lowest energy $5 \mathrm{~d}$ state maximum is situated at $33670 \mathrm{~cm}^{-1}$ with a well-resolved zero phonon line presented in inset of Fig. 1 placed at $33145 \mathrm{~cm}^{-1}$. The energy of this zero phonon line gives the possibility to predict the position of the lowest $\mathrm{f}-\mathrm{d}$ transitions for other lanthanides (Pr-Gd) in $\mathrm{K}_{5} \mathrm{Li}_{2} \mathrm{LnF}_{10}$ crystal [11]. It should be $45385 \mathrm{~cm}^{-1}(220 \mathrm{~nm})$ for praseodymium, $55845 \mathrm{~cm}^{-1}$ $(179 \mathrm{~nm})$ for neodymium, $59645 \mathrm{~cm}^{-1}(168 \mathrm{~nm})$ for samarium, $69045 \mathrm{~cm}^{-1}(145 \mathrm{~nm})$ for europium and $78945 \mathrm{~cm}^{-1}$ $(127 \mathrm{~nm})$ for gadolinium, which is in agreement with observation [13].

In addition to the first crystal field level of the $5 \mathrm{~d}$ state at $33145 \mathrm{~cm}^{-1}$, all four remaining levels were observed at energies $43700,45900,47250$ and $54500 \mathrm{~cm}^{-1}$. This gives

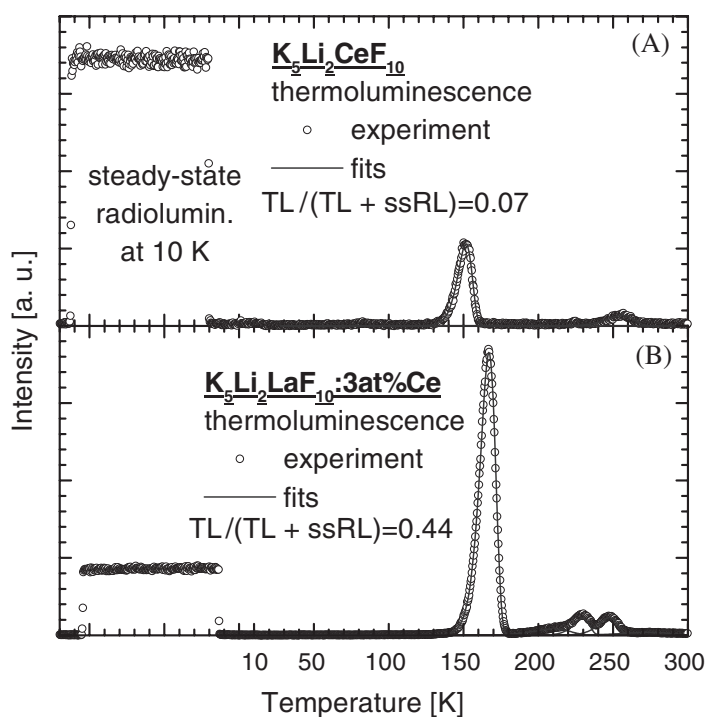

Fig. 2. Glow curves of $\mathrm{K}_{5} \mathrm{Li}_{2} \mathrm{CeF}_{10}$ (A) and $\mathrm{K}_{5} \mathrm{Li}_{2} \mathrm{La}_{0.97} \mathrm{Ce}_{0.03} \mathrm{~F}_{10}$ (B), recorded at heating rate $0.15 \mathrm{~K} / \mathrm{s}$ following a $10 \mathrm{~min}, \mathrm{X}$-ray irradiation.

crystal field splitting, defined as the difference between the lowest and highest $5 \mathrm{~d}$ level, equal to $21355 \mathrm{~cm}^{-1}$, which makes it possible to determine the red shift and calculate the so-called spectroscopic polarizability of ligands in the crystal host [14-16].

Fig. 2 presents the thermoluminescence glow curves of $\mathrm{K}_{5} \mathrm{Li}_{2} \mathrm{CeF}_{10}$ (A) and $\mathrm{K}_{5} \mathrm{Li}_{2} \mathrm{LaF}_{10}$ doped with 3 at\% of $\mathrm{Ce}^{3+}$ (B). In spite of a rather complex structure of most of the glow curves, a characteristic asymmetry of major peaks is apparent, indicating that the simple TL model proposed by Randall and Wilkins [17] may be used to analyze the data. To separate the curves into first-order peaks we have fitted the following well-known Randall-Wilkins formula to experimental points:

$I(T)=\sum_{i} n_{0 i} s \exp \left(-\frac{E}{k_{\mathrm{B}} T}\right) \exp \left(-\frac{s}{\beta} \int_{T_{0}}^{T} \exp \left(-\frac{E}{k_{\mathrm{B}} T^{\prime}}\right) \mathrm{d} T\right)$,

where $I$ denotes the TL intensity, $T$ - the temperature, $\beta$ the heating rate, $n_{0}$ - the initial concentration of traps, $E-$ the trap depth, $s$-the frequency factor, and $k_{\mathrm{B}}$ - the Boltzmann constant. Preliminary input values of $n_{0 i}, E_{i}$, and $s_{i}$ have been chosen by trial and error. The effect of the non-ideal heat transfer [18] has been neglected due to a very low heating rate. The results of the fitting procedure are summarized in Table 1.

As a steady-state radioluminescence intensity during the irradiation prior to the TL runs has also been recorded it is possible to evaluate a ratio, defined as $\mathrm{TL} /(\mathrm{TL}+\mathrm{ssRL})$, indicating the fraction of the total excitation energy that has been accumulated in traps, see Fig. 2 .

\section{Conclusions}

The detail information about the $5 \mathrm{~d}$ levels structure and energies were given. The zero-phonon line was determined 
Table 1

Parameters of traps detected in $\mathrm{K}_{5} \mathrm{Li}_{2} \mathrm{CeF}_{10}$ and $\mathrm{K}_{5} \mathrm{Li}_{2} \mathrm{La}_{0.97} \mathrm{Ce}_{0.03} \mathrm{~F}_{10}$

\begin{tabular}{llllll}
\hline Sample & Peak no. $\begin{array}{l}T_{\max } \\
(\mathrm{K})\end{array}$ & \multicolumn{1}{l}{$n_{0}$} & $E(\mathrm{eV})$ & $\ln s$ \\
\hline $\mathrm{K}_{5} \mathrm{Li}_{2} \mathrm{CeF}_{10}$ & 1 & 152 & 159300 & 0.4063 & 27.61 \\
& 2 & 256 & 38290 & 0.6236 & 24.14 \\
$\mathrm{~K}_{5} \mathrm{Li}_{2} \mathrm{La}_{0.97} \mathrm{Ce}_{0.03} \mathrm{~F}_{10}$ & 1 & 167 & 2668000 & 0.4615 & 28.52 \\
& 2 & 211 & 142700 & 0.296 & 11.89 \\
& 3 & 230 & 167900 & 0.8435 & 39.05 \\
& 4 & 247 & 206000 & 0.8245 & 34.88 \\
& 5 & 274 & 86170 & 0.384 & 11.55 \\
\hline
\end{tabular}

$T_{\max }$ is the temperature (at which the glow curve peaks were observed), $E$ the trap depth, $s$ the frequency factor, $n_{0}$ is in the same units as TL intensity and $s$ is in $\mathrm{s}^{-1}$.

at $33145 \mathrm{~cm}^{-1}(301.70 \mathrm{~nm})$. Recorded TL spectra inform about the frozen energy stored in traps and defects. The low-value of ratio $\mathrm{TL} /(\mathrm{TL}+\mathrm{ssRL})$ for $\mathrm{K}_{5} \mathrm{Li}_{2} \mathrm{CeF}_{10}(0.07)$ suggests that the trapping process is almost negligible. On the contrary, in case of $\mathrm{K}_{5} \mathrm{Li}_{2} \mathrm{La}_{0.99} \mathrm{Ce}_{0.03} \mathrm{~F}_{10}(0.44)$ nearly half of the excitation energy is stored in traps.

\section{Acknowledgements}

This work was supported by the European Community-Research Infrastructure Action under the FP6 "Structuring the European Research Area" Programme (through the Integrated Infrastructure Initiative "Integrating Activity on Synchrotron and Free Electron Laser Science". We are grateful to Toyo Tanso Co., Ltd., Osaka, Japan for providing high quality IG-110 purified graphite.
The Committee for Scientific Research supported this work as research project in 2005-2007.

\section{References}

[1] R.T. Wegh, H. Donker, A. Meijerink, R.J. Lamminmäki J. Hölsä, Phys. Rev. B 56 (1997) 13841.

[2] R.T. Wegh, H. Donker, K.D. Oskam, A. Meijerink, J. Lumin. 82 (1999) 93.

[3] W. Ryba-Romanowski, S. Gołąb, G. Dominiak-Dzik, P. Solarz, Appl. Phys. A 74 (2002) 581.

[4] C.M. Combes, P. Dorenbos, C.W.E. van Eijk, K.W. Krämer, H.U. Güdel, J. Lumin. 82 (1999) 299.

[5] A.V. Gektin, N.V. Shiran, S.V. Neicheva, M.J. Weber, S.E. Derenzo, W.W. Moses, J. Lumin. 102-103 (2003) 460.

[6] A.J. Wojtowicz, W. Drozdowski, D. Wisniewski, J.-L. Lefaucheur, Z. Galazka, Z. Gou, T. Lukasiewicz, J. Kisielewski, Opt. Mater. 28 (2006) 85.

[7] A. Voloshinovskii, Radiat. Meas. 33 (2001) 565.

[8] M. Itoh, M. Ohno, S. Hashimoto, Phys. Rev. Lett. 69 (1992) 1133.

[9] A. Voloshinovskii, I. Pashuk, Ya. Chornodol'skyi, G. Stryganyuk, P. Rodnyi, Phys. Stat. Sol. B 241 (2004) 2613.

[10] S. Asaka, M. Itoh, M. Kamada, Phys. Rev. B 63 (2001) 081104.

[11] P. Dorenbos, J. Lumin. 91 (2000) 91.

[12] P. Solarz, G. Dominiak-Dzik, R. Lisiecki, W. Ryba-Romanowski, Radiat. Meas. 38 (2004) 603.

[13] P. Solarz, G. Dominiak-Dzik, W. Ryba-Romanowski, J. Alloys Compounds 362 (2004) 61 .

[14] P. Dorenbos, Phys. Rev. B 62 (2000) 15640.

[15] P. Dorenbos, Phys. Rev. B 62 (2000) 15650.

[16] P. Dorenbos, Phys. Rev. B 64 (2001) 125117.

[17] J.T. Randall, M.H.F. Wilkins, Proc. Roy. Soc. London A 184 (1945) 366.

[18] T.M. Piters, R. Melendrez, W. Drozdowski, Rad. Prot. Dosim. 84 (1999) 127 